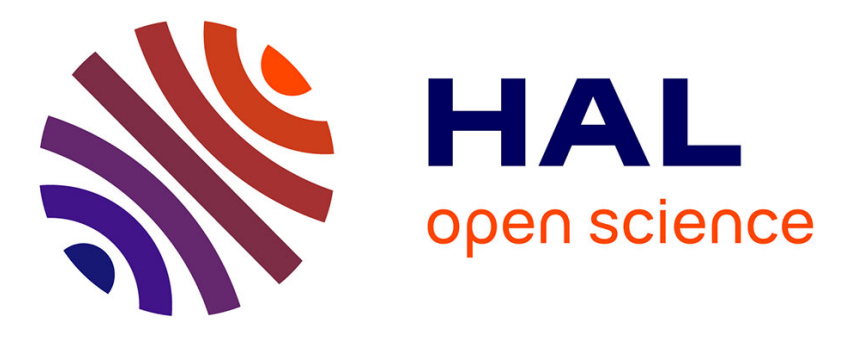

\title{
Superconducting super-organized nanoparticles of the superconductor (BEDT-TTF)2Cu(NCS)2
}

Dominique de Caro, Kane Jacob, Marco Revelli-Beaumont, Christophe Faulmann, Lydie Valade, Marine Tassé, Sonia Mallet-Ladeira, Shuxiang Fan, Tadashi Kawamoto, Takehiko Mori, et al.

\section{To cite this version:}

Dominique de Caro, Kane Jacob, Marco Revelli-Beaumont, Christophe Faulmann, Lydie Valade, et al. Superconducting super-organized nanoparticles of the superconductor (BEDT-TTF)2Cu(NCS)2. Synthetic Metals, 2021, 278 (16), pp.116844. 10.1016/j.synthmet.2021.116844 . hal-03364488

\section{HAL Id: hal-03364488 \\ https://hal.science/hal-03364488}

Submitted on 12 Oct 2021

HAL is a multi-disciplinary open access archive for the deposit and dissemination of scientific research documents, whether they are published or not. The documents may come from teaching and research institutions in France or abroad, or from public or private research centers.
L'archive ouverte pluridisciplinaire HAL, est destinée au dépôt et à la diffusion de documents scientifiques de niveau recherche, publiés ou non, émanant des établissements d'enseignement et de recherche français ou étrangers, des laboratoires publics ou privés. 
Synthetic Metals

\section{Superconducting super-organized nanoparticles of the superconductor (BEDT-TTF $)_{2} \mathrm{Cu}(\mathrm{NCS})_{2}{ }^{\dagger}$}

Dominique de Caro, ${ }^{a,}{ }^{*}$ Kane Jacob, a Marco Revelli-Beaumont, ${ }^{a}$ Christophe Faulmann, b Lydie Valade, a Marine Tassé, a Sonia Mallet-Ladeira, a Shuxiang Fan, ${ }^{c}$ Tadashi Kawamoto, c Takehiko Mori ${ }^{c}$ and Jordi Fraxedas ${ }^{d}$

a LCC-CNRS, Université de Toulouse, CNRS, UPS, F-31077 Toulouse, France.

${ }^{b}$ CEMES-CNRS, Université de Toulouse, CNRS, UPS, F-31055 Toulouse, France.

${ }^{c}$ Department of Materials Science and Engineering, Tokyo Institute of Technology, O-okayama 2-12-1, Meguro-ku, 152-8552, Japan.

${ }^{d}$ Catalan Institute of Nanoscience and Nanotechnology (ICN2), CSIC and BIST, Campus UAB, Bellaterra, Barcelona, 08193, Spain

ABSTRACT. The synthesis of (BEDT-TTF) ${ }_{2} \mathrm{Cu}(\mathrm{NCS})_{2}$ in the presence of poly(ethylene glycol) leads to super-organized nanoparticles of 2 to $8 \mathrm{~nm}$ size. Samples contain crystalline nanoparticles of the $\kappa$-(BEDT-TTF ${ }_{2} \mathrm{Cu}(\mathrm{NCS})_{2}$ phase. The electrical conductivity at room temperature is about $0.08 \mathrm{~S} \cdot \mathrm{cm}^{-1}$, a typical value for nanopowders of tetrathiafulvalene-based conducting compounds. The current-voltage characteristic for an individual nanoparticle aggregate is fitted with a Shockley diode model. A saturation current of $4.1 \mathrm{pA}$ and a threshold voltage of $0.45 \mathrm{~V}$ are extracted. N1s and S2p lines in X-ray photoelectron spectroscopy evidence a charge transfer, characteristic for tetrathiafulvalene-based conducting salts. Magnetic susceptibility studies show a superconducting transition at 9.1 $\mathrm{K}$, a characteristic value for the $\mathrm{K}-(\mathrm{BEDT}-\mathrm{TTF})_{2} \mathrm{Cu}(\mathrm{NCS})_{2}$ phase. The thermoelectric power of the nanopowder is represented by the average $/ / c$ and $/ / b$ values for the single-crystal. Finally, resistivity for the nanopowder is nearly flat in the metallic region.

KEYWORDS. Molecular conductor, superconductor, nanoparticles.

† Electronic Supplementary Information (ESI) available: Powder X-ray diffraction diagram of BEDT_Cu_10 compared with the one calculated from crystal structure of (BEDT-TTF $)_{2} \mathrm{Cu}(\mathrm{NCS})_{2}$ and list of indexed and non-indexed peaks.

\section{Introduction}

The family of superconductors based on the organic BEDT-TTF (bis-ethylenedithiotetrathiafulvalene, Fig. 1) molecule is the series of molecular superconductors exhibiting the largest number of phases and the highest critical temperatures $\left(T_{c}\right)$. In (BEDT-TTF) ${ }_{2} \mathrm{X}$ compounds 
where $\mathrm{X}^{-}$stands for $\mathrm{Cu}(\mathrm{NCS})_{2}^{-}, \mathrm{Cu}\left[\mathrm{N}(\mathrm{CN})_{2}\right] \mathrm{Cl}^{-}$or $\mathrm{Cu}\left[\mathrm{N}(\mathrm{CN})_{2}\right] \mathrm{Br}^{-}, T_{c}$ are in the $8-12 \mathrm{~K}$ range. Black thin plate single crystals of $\kappa-(\mathrm{BEDT}-\mathrm{TTF})_{2} \mathrm{Cu}(\mathrm{NCS})_{2}$ are prepared by electrocrystallization, on a $\mathrm{Pt}$ wire, of a solution containing BEDT-TTF, $\mathrm{Cu}(\mathrm{NCS}), \mathrm{KSCN}$ and 18-crown-6 ether in 1,1,2trichloroethane, chlorobenzene, 1,2-dichloroethane, tetrahydrofurane or ethanol [1]. The crystal structure shows that two BEDT-TTF molecules form a dimerized pair and that the dimers are arranged one another almost perpendicularly $\left(84-87^{\circ}\right)$. As a result of short intra- and inter-dimer S...S atomic contacts, the BEDT-TTF donor molecules build two-dimensional conducting sheets in the $b c$-plane. Every conducting layer is sandwiched by the insulating layers of $\mathrm{Cu}(\mathrm{NCS})_{2}^{-}$anions along the $a$-axis. This compound has also been prepared as deposits on flat conducting surfaces. For instance, thin films of (BEDT-TTF) ${ }_{2} \mathrm{Cu}(\mathrm{NCS})_{2}$ have been grown on indium tin oxide glass, used as the anode [2]. Films are made of plate crystals with sizes of several micrometers and exhibit a semiconducting behavior. Furthermore, nanorod arrays of $\kappa-(B E D T-T T F)_{2} \mathrm{Cu}(\mathrm{NCS})_{2}$ have been produced on a platinum foil or an indium tin oxide glass [3]. The morphologies of the nanorods have been controlled by adjusting the growth current density.

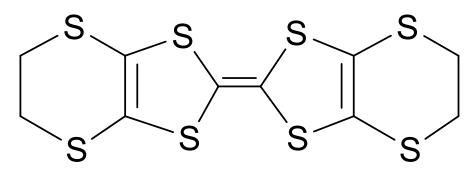

Fig. 1. Bis(ethylenedithio)tetrathiafulvalene.

We have recently reported the synthesis of nanoparticles of the kappa phase of (BEDT$\mathrm{TTF})_{2} \mathrm{Cu}(\mathrm{NCS})_{2}$. They are obtained by the reaction of BEDT-TTF and $\mathrm{Cu}(\mathrm{NCS})_{2}$ in organic solution in the presence of, either long alkyl-chain aconitate esters [4], or $n$-dodecanoic acid [5]. These amphiphilic molecules play the role of growth controlling agent as they create steric hindrance during the particles' nucleation and the growth processes. With aconitate esters, roughly spherical nano-objects are obtained (35-120 nm in size). The largest objects are actually made of aggregated individual small particles ranging from 3 to $10 \mathrm{~nm}$. With $n$-dodecanoic acid, roughly spherical nanoparticles with an average diameter of $28 \mathrm{~nm}$ are grown. These nanoparticles undergo a superconducting transition at $9.1 \mathrm{~K}$. Besides amphiphilic molecules, neutral polymers such as poly(ethylene glycol) (Fig. 2) or polyvinylpyrrolidone have also been used to control the growth of tetrathiafulvalene-based conductors as nanoparticles [6, 7]. Poly(ethylene glycol) is an interesting polymer for stabilizing nanoparticles because it is soluble in both polar and some non-polar solvents and is quite chemically inert and non-toxic. Moreover, 
it successfully stabilized TTF.TCNQ nanoparticles (TTF: tetrathiafulvalene; TCNQ: tetracyanoquinodimethane) [6]. However, in the samples, 5 to $15 \%$ micrometre-sized platelets are observed in addition to spherical nanoparticles. In this article, we report on improved and reproducible synthesis routes producing nanoparticles of $\kappa$-(BEDT-TTF) ${ }_{2} \mathrm{Cu}(\mathrm{NCS})_{2}$ in good yield by using poly(ethyleneglycol) as growth controller, and on the superconducting transition observed for these nanoparticles at nearly the same temperature as for single crystal.

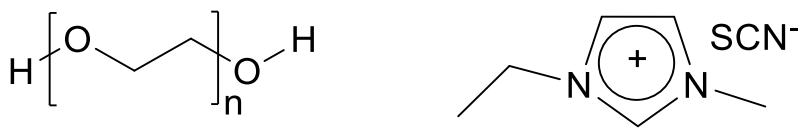

Fig. 2. Poly(ethylene glycol) (left) and 1-ethyl-3-methylimidazolium thiocyanate (right).

\section{Experimental}

\subsection{Materials.}

Solvents are degassed immediately before use. BEDT-TTF, copper(I) thiocyanate Cu(NCS), copper(II) sulfate $\mathrm{CuSO}_{4}$, potassium thiocyanate KSCN, poly(ethylene glycol) 400 (n = 8-9, mean molar mass: $392 \mathrm{~g} \cdot \mathrm{mol}^{-1}$ ) and 1-ethyl-3-methylimidazolium thiocyanate [EMIM][SCN] (figure 2) are commercially available and used without further purification.

\subsection{Syntheses}

$\mathrm{Cu}(\mathrm{NCS})_{2}$ is prepared by adding a water solution of $\mathrm{KSCN}(1.95 \mathrm{~g})$ to an aqueous acidic solution (15 $\left.\% \mathrm{H}_{2} \mathrm{SO}_{4}\right)$ of $\mathrm{CuSO}_{4}(1.60 \mathrm{~g})$ at $0{ }^{\circ} \mathrm{C}$. The black precipitate is filtered off, washed with water and diethylether and finally dried (yield: $65 \%$; elemental analysis, calculated: C $13.4 \%$; $15.6 \%$, found: C $13.2 \%$; N $15.3 \%$ ).

Chemical route for the synthesis of (BEDT-TTF) ${ }_{2} \mathrm{Cu}(\mathrm{NCS})_{2}$ nanoparticles. Solution A: $\mathrm{Cu}(\mathrm{NCS})_{2}(20 \mathrm{mg}$, $0.11 \mathrm{mmol}$ ) and PEG 400 are dissolved by stirring for $15 \mathrm{~min}$ in $50 \mathrm{~mL}$ THF at $25^{\circ} \mathrm{C}$. Solution $\mathrm{B}$ : BEDT-TTF ( $80 \mathrm{mg}, 0.21 \mathrm{mmol}$ ) and PEG 400 are dissolved by stirring for $15 \mathrm{~min}$ in $50 \mathrm{~mL}$ THF at $90^{\circ} \mathrm{C}$. A first half of PEG 400 is added to solution A and a second half to solution $\mathrm{B}$, leading to a total molar ratio of $1,2.5,5,10,15$ or 20 vs. BEDT-TTF. Solution A is dropwise added to solution B at $90^{\circ} \mathrm{C}$ with a flow rate of $1.5 \mathrm{~mL} \cdot \mathrm{min}^{-1}$. After stirring at $90^{\circ} \mathrm{C}$ for $30 \mathrm{~min}$, an air-stable black solid is filtered off, washed with $3 \times 10 \mathrm{~mL}$ hot THF, $10 \mathrm{~mL}$ diethyl ether, and finally dried under vacuum (yield: $65 \%$ ). 
Electrochemical route for the synthesis of $(B E D T-T T F)_{2} C U(N C S)_{2}$ nanoparticles. The synthesis is performed in a one-compartment electrochemical cell equipped with two platinum wire electrodes (length $L=1 \mathrm{~cm}$, diameter $\mathrm{d}=1 \mathrm{~mm}$ ). The distance between the two electrodes is about $1 \mathrm{~cm}$. The cell is filled with BEDT-TTF $(60 \mathrm{mg}, 0.16 \mathrm{mmol}), \mathrm{Cu}(\mathrm{NCS})$ (10 mg, $0.08 \mathrm{mmol})$, [EMIM][SCN] (34 $\mu \mathrm{L}, 0.24 \mathrm{mmol})$, PEG 400 (5, 10, 15, 20 molar eq. vs. BEDTTTF) and $50 \mathrm{~mL} \mathrm{CH} \mathrm{Cl}_{2}$. The electrolysis is conducted at $55^{\circ} \mathrm{C}$ at a constant current density of $\sim 250$ $\mu \mathrm{A} \cdot \mathrm{cm}^{-2}$ under stirring for 1 day. The air-stable black powder of (BEDT-TTF) ${ }_{2} \mathrm{Cu}(\mathrm{NCS})_{2}$ is collected by filtration, washed with $5 \mathrm{~mL}$ portions of dichloromethane and ether, and finally dried under vacuum. Yield: 7 \% for a PEG 400/BEDT-TTF molar ratio of 5, and about $55 \%$ for 10, 15 and 20 molar ratios.

\subsection{Characterization}

Elemental analyses are performed by the Microanalysis Service of LCC-CNRS. Infrared spectra are taken at room temperature (in $\mathrm{KBr}$ matrix) on a Perkin Elmer Spectrum GX spectrophotometer. For transmission electron microscopy (TEM), the samples are sonicated in ether and placed onto a holey carbon-copper grid. Transmission electron microscopy images are taken on a JEOL Model JEM 1011 operating at $100 \mathrm{kV}$. Scanning electron microscopy (SEM) experiments are performed on a MEB-FEG JEOL JSM 7800F Prime. The sample is pasted on a carbon based, electrically conductive, double sided adhesive disc. X-ray photoelectron spectroscopy (XPS) experiments were performed using a SPECS PHOIBOS150 hemispherical analyzer with a monochromatic X-ray source $(1486.6 \mathrm{eV})$ operated at $300 \mathrm{~W}$ in a base pressure in the low $10^{-9}$ mbar. The reported binding energies are referred to the Fermi level of the analyzer. The (BEDT-TTF) ${ }_{2} \mathrm{Cu}(\mathrm{NCS})_{2}$ powder has been dispersed on a conductive carbon tape strip (as in SEM experiments) attached to a sample holder and, after a gentle compression with a clean glass microscope slide, the excess powder is removed with nitrogen gas flow. Powder X-ray diffraction data are recorded at room temperature on a PANalytical X'Pert Pro (Theta-Theta) diffractometer with Cu $K_{\alpha 1}, K_{\alpha 2}$ radiation $(\lambda=1.54059,1.54442$ $\AA$ A). Data collection is performed over the angular range $5^{\circ}<2 \theta<90^{\circ}$ with a step size of $0.017^{\circ}$. Powder conductivity measurements are carried out on pressed pellets of pure powder materials (size: $3.14 \mathrm{~mm}^{2} \times 1 \mathrm{~mm}$ thick) without any grinding. The cylinders used to press the materials play the electrodes role. Resistance data acquisition is achieved using a Hewlett-Packard model 4263A LCR meter. Current-voltage $(I-V)$ curves are acquired on an AFM Smarts SPM 1000 (AIST-NT) in conductivity mode using Au-coated cantilever tips (PPP-NCL Au-10 from Nanosensors. The 
particles are dispersed on a gold substrate previously cleaned with acetone, water, and carefully dried. Magnetic susceptibility is measured using a MPMS-XI QUANTUM DESIGN, operating at an external magnetic field of 10 Oe on a $13.5 \mathrm{mg}$ nanoparticle sample. Thermoelectric power $S$ is measured using a thin film deposited from ethanol suspension of the nanopowder. The samples are attached to two copper heat blocks by carbon paste, and the heat blocks are alternately heated to generate a temperature gradient $\Delta T$ of less than $1 \mathrm{~K}$ [8]. The thermoelectric power was estimated from the generated voltage $\Delta V$ by $S=\Delta V / \Delta T$. By attaching gold wires with carbon paste, conductivity of the thin film was measured.

\section{Results and discussion}

We have reported a two-pot synthetic procedure [5] in which a THF solution of $\mathrm{Cu}(\mathrm{NCS})_{2}$ and $n$ dodecanoic acid is added dropwise to a THF solution of BEDT-TTF and $n$-dodecanoic acid heated at $90^{\circ} \mathrm{C}$. Nanocrystalline $\kappa-(\mathrm{BEDT}-\mathrm{TTF})_{2} \mathrm{Cu}(\mathrm{NCS})_{2}$ precipitates as a black solid. In the present paper, we have applied the same synthetic route by replacing $n$-dodecanoic acid by PEG 400 . Whatever the PEG 400/BEDT-TTF molar ratio $(1,2.5,5,10,15,20)$, the infrared spectrum exhibits two CN vibration modes at $\sim 2067$ and $\sim 2109 \mathrm{~cm}^{-1}$ which are the adequate peaks found in the infrared spectrum of microcrystalline $\kappa-(B E D T-T T F)_{2} \mathrm{Cu}(\mathrm{NCS})_{2}$. However, electron micrographs of these six samples exhibit a majority of micrometre-sized platelets and a few amount of nanoparticles (10 to $70 \mathrm{~nm}$ in size). This chemical method does not allow the selective preparation of nanoparticles and has not been investigated further.

We have previously described the electrochemical synthesis of $\kappa-(B E D T-T T F){ }_{2} \mathrm{Cu}(\mathrm{NCS})_{2}$ as very small nanoparticles [9]. This electrochemical route was performed in a two-compartment electrochemical cell containing BEDT-TTF, Cu(NCS) and the ionic liquid [EMIM][SCN] (EMIM ${ }^{+}: 1-$ ethyl-3-methyl imidazolium, figure 2), acting as supporting electrolyte, provider of an additional $\mathrm{SCN}^{-}$ligand, and finally as a growth controller. The black solid grown on the anode exhibited well dispersed nanoparticles (mean size: $10 \mathrm{~nm}$ ). However, this electrochemical route led to relatively low yields (about $20 \%$ ) and did not show the required reproducibility.

In the present paper, we have studied the combined addition of [EMIM] [SCN] and PEG 400 on the electrochemical growth of (BEDT-TTF $)_{2} \mathrm{Cu}(\mathrm{NCS})_{2}$. In that respect, in a one-compartment electrochemical cell, we have performed the oxidation of BEDT-TTF in a dichloromethane solution of Cu(NCS), [EMIM][SCN] (3 molar eq. vs. Cu(NCS)) and PEG 400 ( 5 to 20 molar eq. vs. BEDT-TTF) at $55^{\circ} \mathrm{C}$ at a constant current density of $\sim 250 \mu A \cdot \mathrm{cm}^{-2}$. 
For a PEG 400/BEDT-TTF molar ratio of 5, the yield is about 7 \%. For PEG 400/BEDT-TTF molar ratios of 10, 15 and 20, yields are close to $55 \%$. Only these last three samples have been further investigated. Their infrared spectra show the two CN vibration modes at 2067 and $2110 \mathrm{~cm}^{-1}$ assigned to $\kappa-(\mathrm{BEDT}-\mathrm{TTF})_{2} \mathrm{Cu}(\mathrm{NCS})_{2}$.

For molar ratios of 15 and 20, electron micrographs show a majority of nanoparticles (10 to $70 \mathrm{~nm}$ in size) in addition to a few amount of micrometre-sized platelets. For a PEG 400/BEDT-TTF molar ratio of 10 (sample further abbreviated as BEDT_Cu_10), electron micrographs evidence the exclusive presence of nanoparticles (Fig. 3). Several possible reasons can explain the control of the growth of (BEDT-TTF $)_{2} \mathrm{Cu}(\mathrm{NCS})_{2}$ as nanoparticles in the presence of both [EMIM][SCN] and PEG 400. We first assume that $\pi-\pi$ interactions can occur between the heterocycle of $\mathrm{EMIM}^{+}$and those of BEDT-TTF. Secondly, PEG 400 can adsorb onto the platinum electrode surface. Therefore, the nucleation process of $(\mathrm{BEDT}-\mathrm{TTF})_{2} \mathrm{Cu}(\mathrm{NCS})_{2}$ is more closely controlled the electrode-solution interface, and the growth process is quickly blocked due to the sterically hindered PEG 400, leading to nanoparticles. As mentioned above, BEDT_Cu_10 is only made of nanoparticles (no micron-sized platelets are observed). Furthermore, it interestingly exhibits nanoparticles organized in domains (Fig. 3). Their individual sizes are in the 2-8 $\mathrm{nm}$ range. They are smaller than those prepared with the only [EMIM] [SCN] as growth controller (90\% of the particles with sizes in the 8-15 $\mathrm{nm}$ range) [9]. This shows the effective combination of [EMIM][SCN] and PEG 400 (10 molar eq. vs. BEDT-TTF) in the growth control and organization of (BEDT-TTF) ${ }_{2} \mathrm{Cu}(\mathrm{NCS})_{2}$ particles.

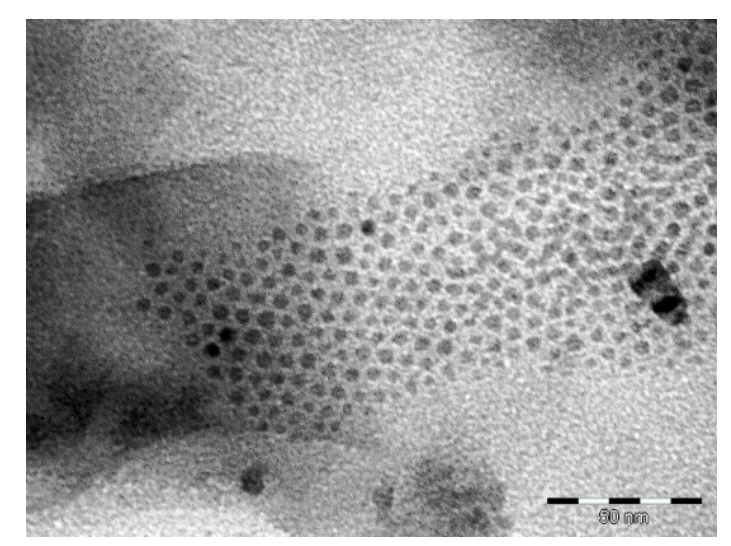

Fig. 3. TEM image for BEDT_Cu_10 (bar = $50 \mathrm{~nm})$.

Scanning electron micrographs confirm the presence of roughly spherical nanoparticles (Fig. 4). Layers of hexagonal superstructures recall the organisation observed by TEM on Fig. 3 for a single layer of nanoparticles: these layers organise along stacks which end with a cauliflower-shaped structure. 
The powder X-Ray diffraction diagram (ESI+) is in agreement with that of the $\kappa-(B E D T-$ $\mathrm{TTF})_{2} \mathrm{Cu}(\mathrm{NCS})_{2}$ phase, alike the one previously reported $[9,10]$.
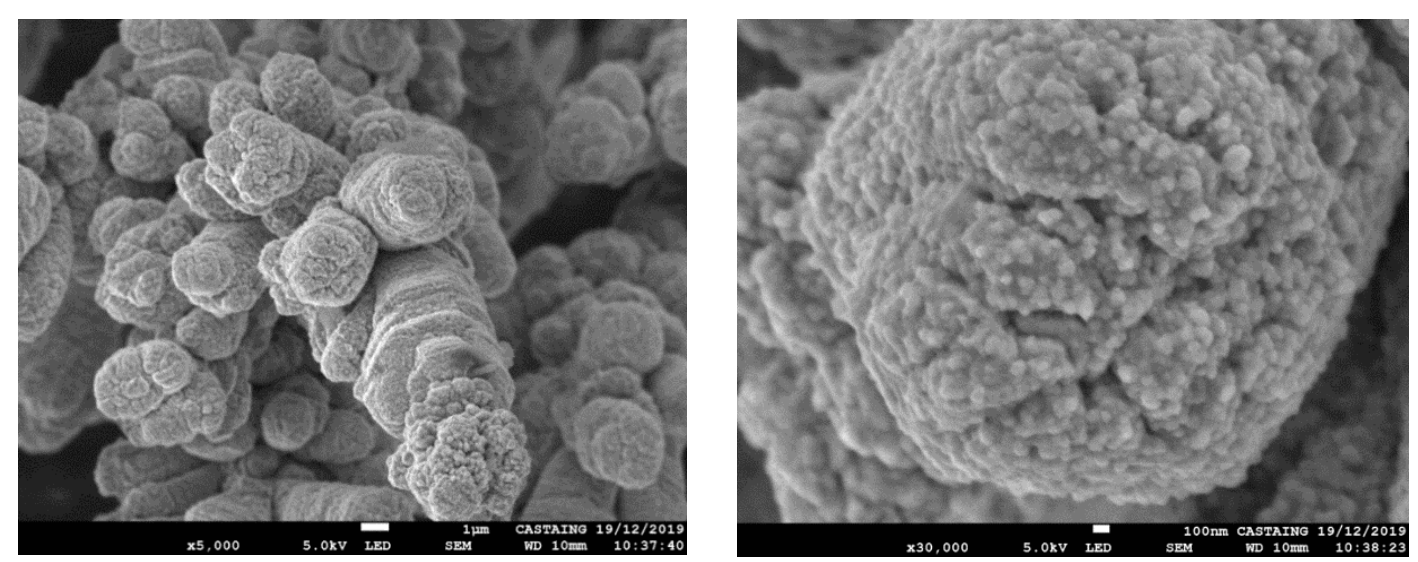

Fig. 4. SEM images for BEDT_Cu_10 (left: bar $=1 \mu \mathrm{m}$; right: bar $=100 \mathrm{~nm}$ ).

Infrared spectrum for BEDT_Cu_10 is shown in Fig. 5. The $v_{\text {c-s }}$ stretching mode is observed at 875 $\left(\mathrm{m}, v_{49} \mathrm{~b}_{2 \mathrm{u}}\right) \mathrm{cm}^{-1}$, a similar value to that reported for a polycrystalline powder of $\kappa$-(BEDT$\mathrm{TTF})_{2} \mathrm{Cu}(\mathrm{NCS})_{2}$ [11], i.e., $880(\mathrm{~m}) \mathrm{cm}^{-1}$. The $v_{\mathrm{c}=\mathrm{c}}$ stretching vibrations are located at $1445\left(\mathrm{~m}, \mathrm{v}_{27}\right.$ $\left.b_{1 u}\right), 1408\left(m, v_{27} b_{1 u}\right)$ and $1316\left(s, v_{3} a_{g}\right) \mathrm{cm}^{-1}$. Their positions are very close to those reported for polycrystalline samples [11]: 1445 (w), 1408 (w) and 1320 (vs) cm ${ }^{-1}$. The two bands at 1445 and $1408 \mathrm{~cm}^{-1}$ are assigned to the same $v_{27} b_{1 u}$ vibration mode. The authors of ref. 11 assume that this mode is coupled with the intramolecular charge transfer. This fact supports the occurrence of electron-molecular vibration (e-mv) coupling with $v_{27} b_{1 u}$ mode. As we also observe these two infrared bands in BEDT_Cu_10, e-mv couplings are also present in the nanocrystalline powder, thus confirming the conducting character of the sample. BEDT_Cu_10 exhibits a roomtemperature conductivity of about $0.08 \mathrm{~S} \cdot \mathrm{cm}^{-1}$. This value is much lower than that reported for a $\kappa$-(BEDT-TTF $)_{2} \mathrm{Cu}(\mathrm{NCS})_{2}$ microcrystalline powder (about $10 \mathrm{~S} \cdot \mathrm{cm}^{-1}$ ) [12]. Nanoparticles could be covered by ionic liquid and/or polymer, presumably as a very thin shell at the particle surface. This results in an increase of interparticle resistances in comparison with microcrystalline powders, leading to lower electrical conductivities. 


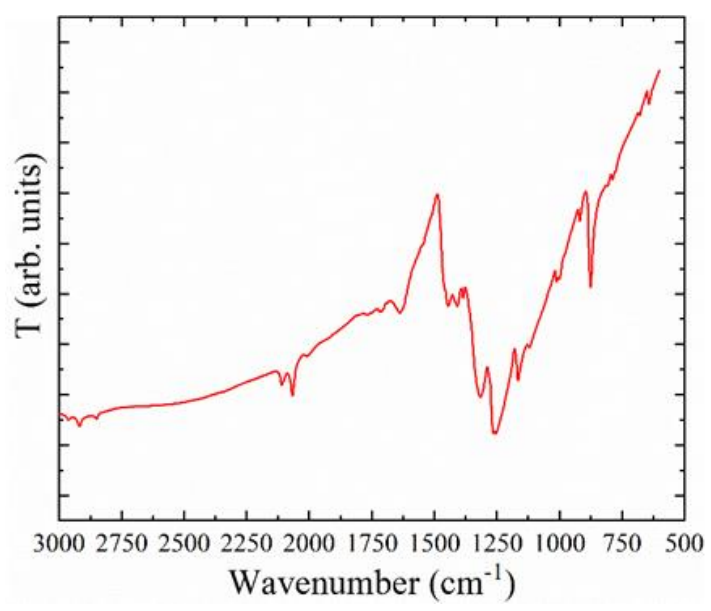

Fig. 5. Infrared spectrum for BEDT_Cu_10.

Fig. 6 shows high resolution experimental XPS spectra (black dots) of the N1s (Fig. 6(a)) and S2p lines (Fig. 6(b)), respectively, with the corresponding least-squares fits using the CasaXPS software [13], after a Shirley-type background subtraction (continuous grey line) using a combination of Gaussian (90\%) and Lorentzian (10\%) functions under the constraint of identical full width at half maximum (FWHM) for all components. The envelope from the fits, represented by orange lines, closely follows the experimental data. Fig. 6(c) shows the spectrum corresponding to the Cu2p core level region. The N1s core level region exhibits two main features at 398.3 (red line) and $401.7 \mathrm{eV}$ (olive line), respectively, and a shoulder at $399.7 \mathrm{eV}$ (blue line). Both 398.3 and $401.7 \mathrm{eV}$ lines are ascribed to the contributions for $\mathrm{Cu}(\mathrm{NCS})_{2}{ }^{-}$(and perhaps also from residual $\mathrm{SCN}^{-}$anions) [14] and $\mathrm{EMIM}^{+}$[15], respectively. We assign the $399.7 \mathrm{eV}$ shoulder to neutral $\mathrm{Cu}(\mathrm{NCS})$ species, in analogy to similar contributions observed in TCNQ salts $[16,17]$. We thus observe, apart from the contribution from $\mathrm{Cu}(\mathrm{NCS})_{2}{ }^{-}$anion, the presence of 1-ethyl-3-methylimidazolium, which was not completely eliminated after the purification of the synthesized powder. Fig. 6(b) shows a complex line shape for the S2p core level. Here, the least-squares fit has been performed with a fixed spinorbit splitting of $1.18 \mathrm{eV}$ and a $\mathrm{S} 2 \mathrm{p}_{1 / 2}$ to $\mathrm{S} 2 \mathrm{p}_{3 / 2}$ branching ratio of 0.5 for all components. The main feature (blue line at $163.6 \mathrm{eV}$ ) corresponds to neutral BEDT-TTF species while the contribution from BEDT-TTF ${ }^{+}$is located at $164.6 \mathrm{eV}$ (red line). The observation of both species is characteristic from charge transfer salts, as previously discussed in the literature $[17,18]$. According to Itti et al. [14], the contribution from $\mathrm{Cu}(\mathrm{NCS})_{2}{ }^{-}$should have a binding energy of about $165.5 \mathrm{eV}$, which corresponds to the green line in the Fig. 6(b). In addition, we observe a contribution from the $\mathrm{CuSO}_{4}$ used in the preparation of the starting $\mathrm{Cu}(\mathrm{NCS})_{2}$ complex, represented by the (wine) line with $168.3 \mathrm{eV}$ binding energy. Finally, two weak features at lower energies, namely at $161.8 \mathrm{eV}$ (olive line) and $162.4 \mathrm{eV}$ (magenta line), are also observed. Such energies are too low for the 
characteristic C-S bonds but are in the range of metal-sulfur bonds [19], so that it may tentatively be assigned to $\mathrm{Cu}-\mathrm{S}$ that may have formed during the electrochemical reaction. From Fig. 6(c), we observe that the main contribution from copper is the $\mathrm{Cu}(\mathrm{I})$ configuration, with traces of $\mathrm{Cu}(\mathrm{II})$ most probably from residual $\mathrm{CuSO}_{4}$ used in the preparation of the starting $\mathrm{Cu}(\mathrm{NCS})_{2}$ complex.
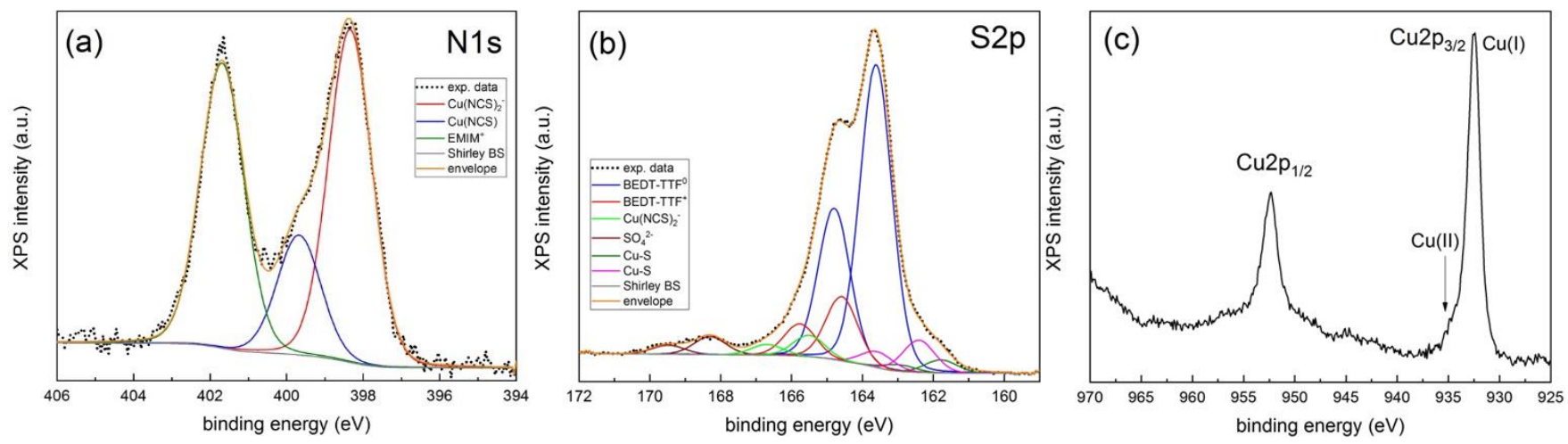

Fig. 6 High resolution XPS spectra for BEDT_Cu_10 corresponding to (a) N1s, (b) S2p and (c) Cu2p core levels of the asreceived sample. Details of the least-squares fits are given in the main text.

Fig. $7($ a) shows the $I-V$ curve of an individual nanoparticle aggregate obtained from conductive atomic force microscopy. The non-linearity of the $I-V$ curve might be attributed to the non-Ohmic character of the contact due to an imperfect interface between the tip and the nanoparticle aggregate. In the linear part of the curve, the observed energy gap is about $0.95 \mathrm{eV}$. A leastsquares fit of the region corresponding to positive bias voltages (from 0.00 to $2.00 \mathrm{~V}$ ) is shown on Fig. 7(b). The fit is obtained using the Shockley diode equation:

$$
I=I_{0}\left[e^{\frac{V}{V_{0}}}-1\right]
$$

where $I_{0}$ represents the saturation current and $V_{0}$ the threshold voltage (energy barrier). From the fit, we obtain $I_{0}=4.1 \pm 0.1 \mathrm{pA}$ and $V_{0}=0.450 \pm 0.004 \mathrm{~V}$ (coefficient of determination: $R^{2}=0.998$ ). The activation energy barrier extracted from the fit, i.e. $0.450 \mathrm{eV}$, is in relatively good agreement with half of the energy gap $(0.95 / 2=0.475 \mathrm{eV})$. 

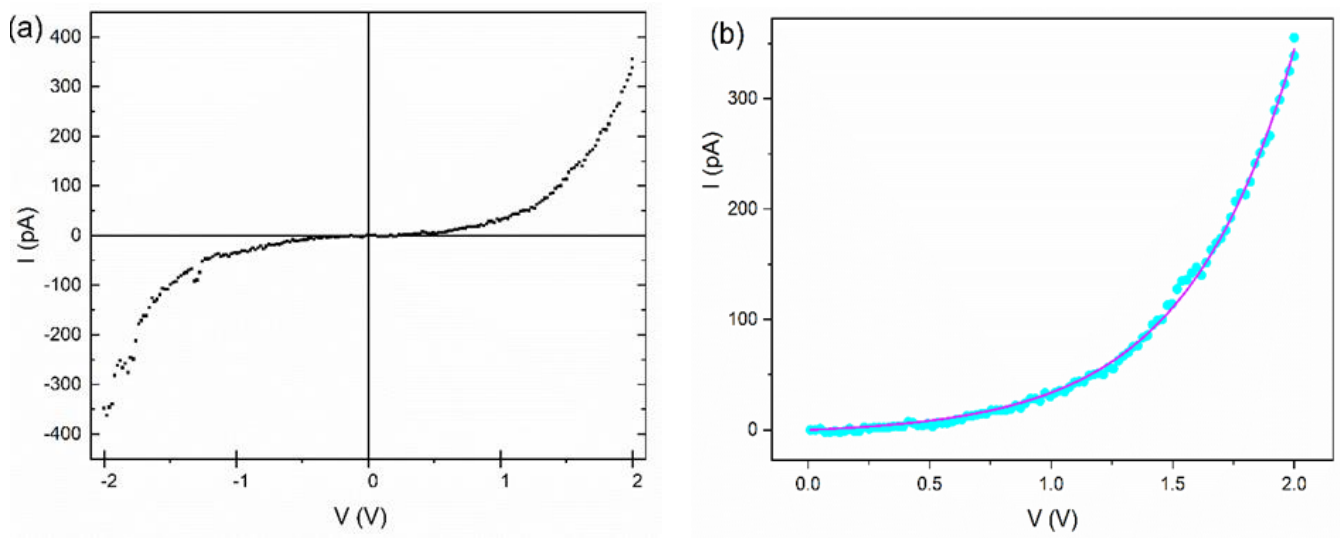

Fig. 7. I-V curve for an individual nanoparticle aggregate (a) and least-square fit of the positive bias voltage (b).

Fig. 8 shows the d.c. volume susceptibility $\left(\chi_{\text {vol }}\right)$ of BEDT_Cu_10 as a function of temperature. The volume magnetic susceptibility is measured at 10 Oe in zero-field cooling (ZFC) and field cooling (FC) mode. ZFC represents the effect of diamagnetic shielding whereas FC represents the effect of magnetic field expulsion (Meissner effect). The magnetization starts to decrease at $9.1 \mathrm{~K}$. This temperature corresponds to the superconducting transition temperature $\left(T_{c}\right)$ of BEDT_Cu_10 nanoparticles. The critical temperature value measured on nanoparticles is very close to that for bulk $\kappa-(\mathrm{BEDT}-\mathrm{TTF})_{2} \mathrm{Cu}(\mathrm{NCS})_{2}$ measured in the ZFC/FC mode at 100 Oe (9.4 K) [20]. A similar effect has been observed for colloidal $\mathrm{Pb}$ nanoparticles, where $T_{c}=6.9 \mathrm{~K}$ for diameters between 16 and $20 \mathrm{~nm}$ while for bulk lead the critical temperature is $7.2 \mathrm{~K} \mathrm{[21].} \mathrm{The} \mathrm{Meissner} \mathrm{(FC)} \mathrm{to} \mathrm{shielding} \mathrm{susceptibility}$ (ZFC) ratio gives a lower bound to the superconducting volume fraction. From the ratio $\chi_{\text {vol }(\mathrm{FC})} /$

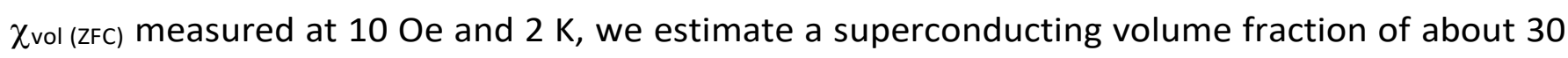
\% for BEDT_Cu_10. It should be noted that it is a rough estimation since the anisotropy and demagnetization factors may modify this value. By taking this remark into account, the FC-ZFC ratio obtained for BEDT_Cu_10 is in agreement with those of previously isolated $28 \mathrm{~nm}$ diameter nanoparticles [5] and bulk [22] $\kappa-(B E D T-T T F)_{2} \mathrm{Cu}(\mathrm{NCS})_{2}$ (about $\left.40 \%\right)$. The dispersed nanoparticles observed by TEM (figure 3) are actually organized as nanoparticle aggregates (sizes in the 40-100 $\mathrm{nm}$ range, as evidenced by SEM, Fig. 4). This super-structure organisation do not prevent superconductivity to develop and occur at a critical temperature similar to that for bulk $\kappa-(B E D T-$ $\mathrm{TTF})_{2} \mathrm{Cu}(\mathrm{NCS})_{2}$, in line with previous results observed for nanoparticles of Bechgaard salts [23]. These results indicate that the coherence length is shorter than $40 \mathrm{~nm}$, in agreement with data for the bulk ( $7.5 \mathrm{~nm}$ for the in-plane coherence length and $0.5 \mathrm{~nm}$ for the out-of-plane coherence length) [24]. 


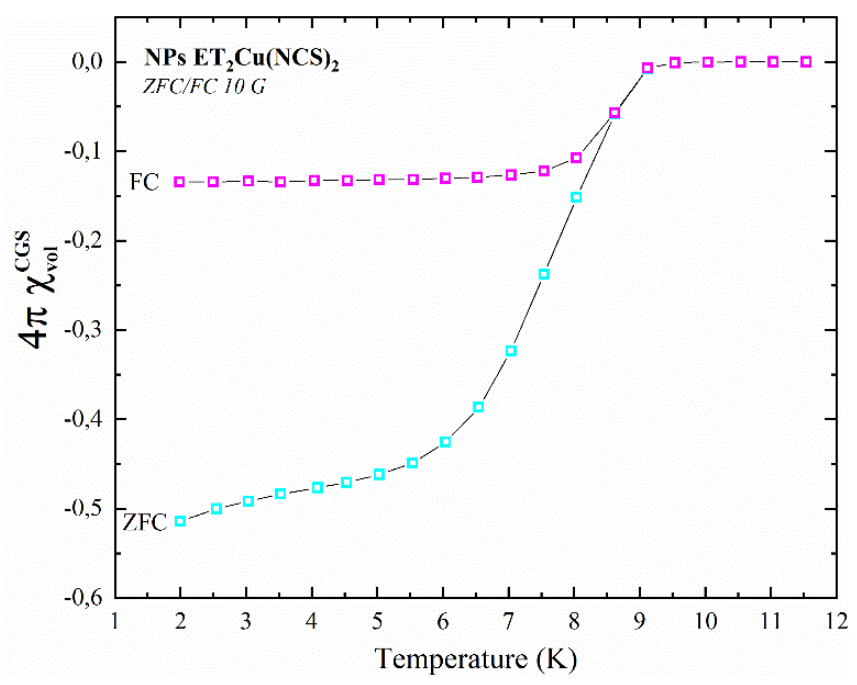

Fig. 8. Temperature dependence of the d.c. volume susceptibility in the zero-field cooling (ZFC) and field cooling (FC) mode for BEDT_Cu_10.

As shown in Fig. 9, the thermoelectric power $S$ of the nanopowder is close to zero. This is contrasting to the thermoelectric power for the single crystal [25], which is comparatively large, reflecting the strong correlation [26]. The thermoelectric power of the single crystal is, however, positive for $/ / c$, while negative for $/ / b$ owing to the Fermi surface [26]. The nanopowder $S$ is approximated by the average. This is reasonable if the nanopowder $S$ is represented by the weighted average

$$
S=\frac{\sigma_{c} S_{c}+\sigma_{b} S_{b}}{\sigma_{c}+\sigma_{b}}
$$

and approximately $\sigma_{c}=\sigma_{b}$.

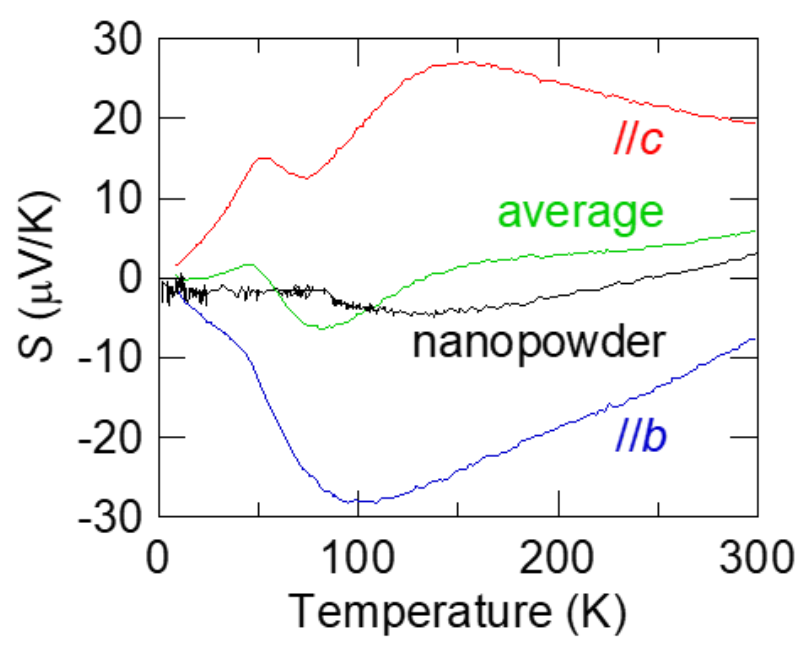

Fig. 9. Thermoelectric power S for BEDT_Cu_10 nanopowder together with the single crystal results.[25] 
Resistivity of the nanoparticle film is shown in Figure 10. The single crystal resistivity increases down to $100 \mathrm{~K}$ due to the strong correlation, but turns to metallic below $100 \mathrm{~K}$ [27]. In the nanoparticles, the resistivity is nearly flat in the metallic region, but the slope changes around 100 $\mathrm{K}$.
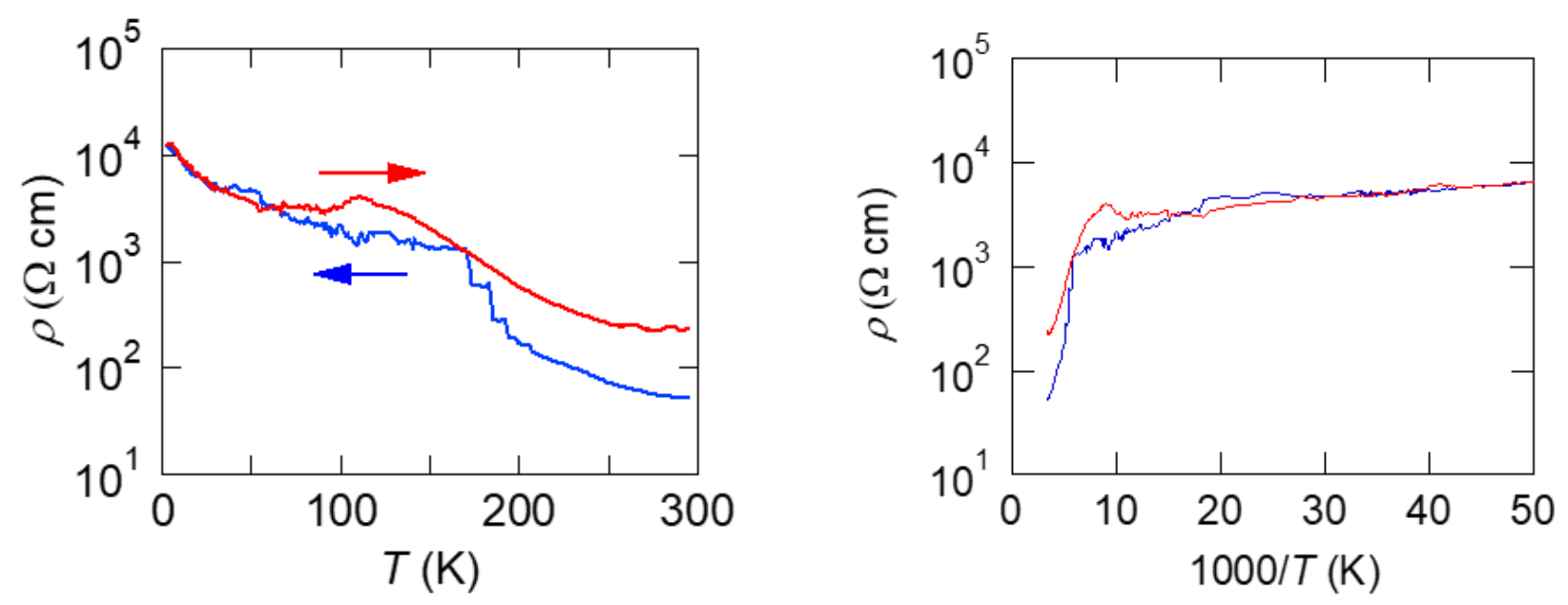

Fig. 10. Resistivity for BEDT_Cu_10, measured in the cooling and heating runs (vs. $T$, left; vs. $1 / T$, right).

\section{Conclusion}

In this paper, we reported on the electrosynthesis of super-organized nanoparticles of the molecular superconductor $\kappa-(\mathrm{BEDT}-\mathrm{TTF})_{2} \mathrm{Cu}(\mathrm{NCS})_{2}$. The growth controller was a combination of an imidazolium-based ionic liquid, i.e. [EMIM][SCN], and poly(ethylene glycol). According to transmission electron microscopy, their sizes were in the $2-8 \mathrm{~nm}$ range and XPS evidences the presence of charge transfer. This low size was remarkable for tetrathiafulvalene-based materials which usually tended to grow as elongated objects and does not affect the structure of this molecular conductor, as reflected by the X-ray diffraction pattern. Magnetic measurements in zero-field cooling and field cooling mode confirmed the observation of a superconducting transition at $T_{c} \sim 9.1 \mathrm{~K}$ for nanoparticles. Finally, the resistivity for nanoparticle powders is nearly flat in the metallic region. Despite a low electrical conductivity of about $10^{-1} \mathrm{~S} \cdot \mathrm{cm}^{-1}$, this material might have a potential interest in organic thermoelectric devices since their morphology should favor a lower thermal conductivity thanks to the nanoscale size of the particles, and then this should increase the thermoelectric figure of merit, ZT. Works are currently in progress to determine ZT. 


\section{Author Contributions}

D.d.C., L.V. and C.F. initiated this work. They also conceived and designed the syntheses and, finally, they wrote the paper. K.J. performed nanoparticle syntheses and characterization of the samples by electron microscopy (TEM and SEM). M.R-B. performed infrared analysis and magnetic susceptibility measurements. M.T. recorded current-voltage curves. S.M-L. performed and interpreted powder X-ray diffraction. S.F., T.K. and T.M. performed resistivity measurements and investigated the thermoelectric power on nanoparticles, both in a large temperature range. J.F. investigated $\mathrm{X}$-ray photoelectron spectroscopy on nanoparticle powders.

\section{Conflicts of interest}

There are no conflicts to declare.

\section{Acknowledgements}

This work has been supported by the Centre National de la Recherche Scientifique (CNRS). M. R. B. thanks the Ministère de l'Enseignement Supérieur et de la Recherche for a doctoral grant. This research was supported by the Spanish Ministry of Economy and Competitiveness (MINECO) under Contract No. PGC2018-095032-B-100. The ICN2 is funded by the CERCA program/Generalitat de Catalunya. The ICN2 is supported by the Severo Ochoa program of MINECO (Grant SEV-2017-0706). This work was partly supported by the JSPS KAKENHI Grant Number 18H02044, and the Takahashi Industrial and Economic Research Foundation (08-003022).

\section{References}

[1] G. Saito, Physica C, 162-164 (1989) 577-582. https://doi.org/10.1016/0921-4534(89)91162-3.

[2] H. Awano, K. Kawase, M. Asai, H. Ohigashi, S. Ohshima, K. Akiyama and M. Kato, Japanese Journal of Applied Physics, 31 (1992) 1899-1900. https://iopscience.iop.org/article/10.1143/JJAP.31.1899.

[3] C. S. Huang, Y. Zhang, H. B. Liu, S. Cui, C. R. Wang, L. Jiang, D. P. Yu, Y. L. Li and D. B. Zhu, Journal of Physical Chemistry C, 111 (2007) 3544-3547. https://doi.org/10.1021/jp067449k.

[4] B. Cormary, C. Faulmann, D. de Caro, L. Valade, P. de Caro, B. Ballesteros and J. Fraxedas, Comptes Rendus Chimie, 21 (2018) 809-813. https://doi.org/10.1016/i.crci.2018.07.006. 
[5] M. Revelli-Beaumont, C. Faulmann, D. de Caro, M. Cazayous, Y. Gallais, A. Sacuto, C. Pasquier, P. Auban Senzier, M. Monteverde, K. Jacob and L. Valade, Synthetic Metals, 261 (2020) 116310. https://doi.org/10.1016/j.synthmet.2020.116310.

[6] D. de Caro, L. Valade, C. Faulmann, K. Jacob, D. Van Dorsselaer, I. Chtioui, L. Salmon, A. Sabbar, S. El Hajjaji, E. Perez, S. Franceschi and J. Fraxedas, New Journal of Chemistry, 37 (2013) 3331-3336. http://dx.doi.org/10.1039/C3NJ00555K.

[7] T. Kadoya, D. de Caro, K. Jacob, C. Faulmann, L. Valade and T. Mori, Journal of Materials Chemistry, 21 (2011) 18421-18424. http://dx.doi.org/10.1039/C1JM12783G.

[8] R. Sato, Y. Kiyota, T. Kadoya, T. Kawamoto and T. Mori, RSC Advances, 6 (2016) 41040-41044. https://doi.org/10.1039/C6RA04455G.

[9] D. de Caro, C. Faulmann, L. Valade, K. Jacob and B. Cormary, French-Ukrainian Journal of Chemistry, 4 (2016) 65-75. http://dx.doi.org/10.17721/fujcV4I1P65-75.

[10] Crystallographic data: Monoclinic, Space group P2 1 ; refined cell for BEDT_Cu_10: a = 16.255(3), b= 8.457(1), $c=13.142(3) \AA ; \beta=110.297(3) ; V=1694.5 \AA^{3}$ to be compared to $a=16.256(3), b=8.4564(13)$, $c=13.143(3) \AA ; \beta=110.276(14)^{\circ} ; V=1694.776 \AA^{3}$. .

[11] R. Swietlik, C. Garrigou-Lagrange, C. Sourisseau, G. Pages and P. Delhaes, Journal of Materials Chemistry, 2 (1992) 857-864. https://doi.org/10.1039/JM9920200857.

[12] T. Mori, Electronic properties of organic conductors, 1st ed., Springer, 2016.

[13] J. Walton, P. Wincott, N. Fairley and A. Carrick, Peak Fitting with CasaXPS Accolyte Science, Knutsford, UK, 2010.

[14] R. Itti, H. Mori, K. Ikeda, I. Hirabayashi, N. Koshizuka and S. Tanaka, Physica C, 185 (1991) 2673-2674. https://doi.org/10.1016/0921-4534(91)91458-G.

[15] O. Höfft, S. Bahr, M. Himmerlich, S. Krischok, J. A. Schaefer and V. Kempter, Langmuir, 22 (2006) $7120-$ 7123. https://doi.org/10.1021/la060943v.

[16] C. Rojas, J. Caro, M. Grioni and J. Fraxedas, Surface Science, 482-5 (2001) 546-551. https://doi.org/10.1016/S0039-6028(01)00715-4.

[17] M. Sing, U. Schwingenschlögl, R. Claessen, M. Dressel and C. S. Jacobsen, Physical Review B, 67 (2003) 125402. https://doi.org/10.1103/PhysRevB.67.125402.

[18] J. Fraxedas, S. García-Gil, S. Monturet, N. Lorente, I. Fernández-Torrente, K. J. Franke, J. I. Pascual, A. Vollmer, R. P. Blum, N. Koch and P. Ordejón, Journal of Physical Chemistry C 115 (2011) 18640-18648. https://doi-org.inc.bib.cnrs.fr/10.1021/ip2050838. 
[19] I. Malfant, K. Rivasseau, J. Fraxedas, C. Faulmann, D. De Caro, L. Valade, L. Kaboub, J. M. Fabre and F. Senocq, Journal of the American Chemical Society, 128 (2006) 5612-5613. https://doiorg.inc.bib.cnrs.fr/10.1021/ja060690s.

[20] M. Tokumoto, H. Anzai, K. Takahashi, K. Murata, N. Kinoshita and T. Ishiguro, Synthetic Metals, 27 (1988) A305-A310. https://doi.org/10.1016/0379-6779(88)90416-X.

[21] P. Zolotavin and P. Guyot-Sionnest, ACS Nano, 4 (2010) 5599-5608. 10.1021/nn102009g.

[22] H. Veith, C.-P. Heidmann, H. Müller, H. P. Fritz, K. Andres and H. Fuchs, Synthetic Metals, 27 A (1988) 361-365. https://doi.org/10.1016/0379-6779(88)90424-9.

[23] L. E. Winter, E. Steven, J. S. Brooks, S. Benjamin, J.-H. Park, D. de Caro, C. Faulmann, L. Valade, K. Jacob, I. Chtioui, B. Ballesteros and J. Fraxedas, Physical Review B, 91 (2015) 035437. https://doi.org/10.1103/PhysRevB.91.035437.

[24] S. Friemel, C. Pasquier, Y. Loirat and D. Jerome, Physica C, 259 (1996) 181-186. https://doi.org/10.1016/0921-4534(95)00809-8.

[25] H. Urayama, H. Yamochi, G. Saito, T. Sugano, M. Kinoshita, T. Inabe, T. Mori, Y. Maruyama and H. Inokuchi, Chemistry Letters, (1988) 1057-1060. https://doi.org/10.1246/cl.1988.1057.

[26] T. Mori and H. Inokuchi, Journal of the Physical Society of Japan, 57 (1988) 3674-3677. https://doi.org/10.1143/JPSJ.57.3674.

[27] H. Urayama, H. Yamochi, G. Saito, K. Nozawa, T. Sugano, M. Kinoshita, S. Sato, K. Oshima, A. Kawamoto and J. Tanaka, Chemistry Letters, 17 (1988) 55-58. https://doi.org/10.1246/cl.1988.55. 
Superconducting super-organized nanoparticles of the superconductor (BEDT-TTF) ${ }_{2} \mathrm{Cu}(\mathrm{NCS})_{2}$

\section{ESI content}

- Powder X-ray diffraction diagram of BEDT_Cu_10 compared with the one calculated from crystal structure of (BEDT-TTF $)_{2} \mathrm{Cu}(\mathrm{NCS})_{2}$

- List of indexed and non-indexed peaks.

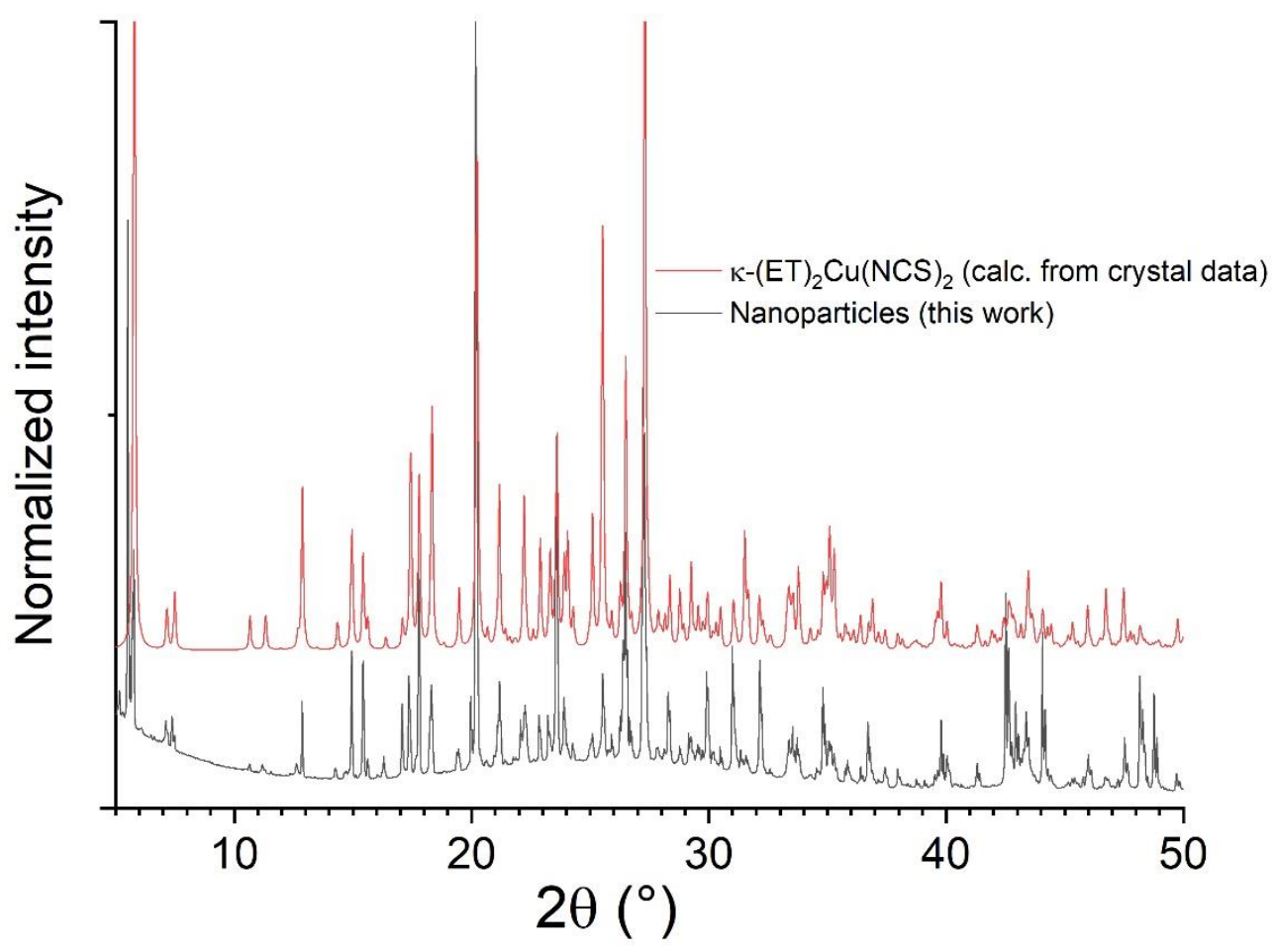

Powder X-ray diffraction diagram of BEDT_Cu_10 compared with the one calculated form crystal structure of (BEDT$\mathrm{TTF})_{2} \mathrm{Cu}(\mathrm{NCS})_{2}$ 


\section{Relevant parameters of BEDT_Cu_10}

Bibliographic data:

Audit creation date:

1989-01-20

Audit creation method:

CSD-ConQuest-V1

Author name:

K.D.Carlson, U.Geiser, A.M.Kini, H.H.Wang, L.K.Montgomery, W.K.Kwok, M.A.Beno, J.M.Williams, C.S.Cariss, G.W.Crabtree

Chemical name systematic: bis(bis(Ethylenedithio)tetrathiafulvalene) di-isothiocyanato-copper

Formula sum: $\mathrm{C}_{22} \mathrm{H}_{16} \mathrm{Cu}_{1} \mathrm{~N}_{2} \mathrm{~S}_{18}$

Journal name: Inorg.Chem.

Journal volume: 27

Page first: 965

Structure and profile data:

Formula sum: $\mathrm{Cu}_{2.00} \mathrm{~S}_{36.00} \mathrm{~N}_{4.00} \mathrm{C}_{44.00}$

Formula mass/ g/mol: 1865.7630

Density (calculated) $/ \mathrm{g} / \mathrm{cm}^{3}$

1.8281

$\mathrm{F}(000)$ : 926.0000

Mass Absorption Coefficient/ $\mathrm{cm}^{\wedge} 2 / \mathrm{g}: \quad 60.4901$

Volume fraction/ \%: 100.0000

Weight fraction/ \%: 100.000000

Space group (No.): P 1211 (4)

Lattice parameters:
a/ A:
16.255(3)
b/ $\AA$ :
8.457(1)
c/ $\AA$ :
13.142(3)
alpha/ ${ }^{\circ}$ :
90
beta/ ${ }^{\circ}$ :
110.297(3)
gamma/ ${ }^{\circ}$ :
90
V/ $10^{6} \mathrm{pm}^{3}$
1694.50000

\section{$\underline{\text { Non-indexed peaks }}$}

$\begin{array}{llll}\text { No. } & \text { 2Th. (o) }\left[{ }^{\circ}\right] & \text { d-sp. (o) }[\AA ̊ & \text { Rel. Int. [\%] } \\ 1 & 5.1628 & 17.103160 & 4.36 \\ 2 & 5.5102 & 16.025440 & 67.50 \\ 3 & 5.6083 & 15.745310 & 9.25 \\ 4 & 7.3804 & 11.968240 & 5.28 \\ 5 & 19.9724 & 4.442046 & 10.33 \\ 6 & 26.5557 & 3.353881 & 15.26\end{array}$




\section{Indexed peaks}

\begin{tabular}{|c|c|c|c|c|c|c|c|c|}
\hline No. & $\mathrm{h}$ & $\mathrm{k}$ & I & 2Th. (c) $\left[{ }^{\circ}\right]$ & 2Th. (o) $\left[^{\circ}\right]$ & $2 \operatorname{Th} .(\mathrm{d})\left[^{\circ}\right]$ & d-sp. (c) $[\AA]$ & d-sp. (o) \\
\hline 1 & 1 & 0 & 0 & 5.7922 & 5.7623 & 0.0300 & 15.245800 & 15.325000 \\
\hline 2 & 0 & 0 & 1 & 7.1660 & 7.1440 & 0.0219 & 12.325950 & 12.363710 \\
\hline 3 & 1 & 0 & -1 & 7.4914 & 7.4780 & 0.0134 & 11.791270 & 11.812310 \\
\hline 4 & 1 & 0 & 1 & 10.6724 & 10.6448 & 0.0275 & 8.282834 & 8.304196 \\
\hline 5 & 2 & 0 & -1 & 11.3251 & 11.1930 & 0.1321 & 7.806897 & 7.898732 \\
\hline 6 & 0 & 1 & 1 & 12.6836 & 12.6176 & 0.0659 & 6.973598 & 7.009898 \\
\hline 7 & 1 & 1 & -1 & 12.8713 & 12.8673 & 0.0040 & 6.872332 & 6.874458 \\
\hline 8 & 0 & 0 & 2 & 14.3601 & 14.2664 & 0.0938 & 6.162977 & 6.203271 \\
\hline 9 & 1 & 1 & 1 & 14.9590 & 14.9488 & 0.0102 & 5.917564 & 5.921581 \\
\hline 10 & 2 & 1 & -1 & 15.4341 & 15.4351 & -0.0011 & 5.736479 & 5.736083 \\
\hline 11 & 2 & 0 & 1 & 15.6337 & 15.6250 & 0.0087 & 5.663672 & 5.666799 \\
\hline 12 & 3 & 0 & -1 & 16.3862 & 16.3036 & 0.0826 & 5.405236 & 5.432424 \\
\hline 13 & 1 & 1 & -2 & 17.0945 & 17.0704 & 0.0241 & 5.182831 & 5.190095 \\
\hline 14 & 3 & 0 & 0 & 17.4365 & 17.3579 & 0.0786 & 5.081934 & 5.104771 \\
\hline 15 & 0 & 1 & 2 & 17.7934 & 17.7675 & 0.0260 & 4.980797 & 4.988015 \\
\hline 16 & 2 & 1 & -2 & 18.3290 & 18.3089 & 0.0201 & 4.836457 & 4.841716 \\
\hline 17 & 3 & 1 & -1 & 19.4744 & 19.4249 & 0.0495 & 4.554492 & 4.565980 \\
\hline 18 & 1 & 1 & 2 & 20.2326 & 20.1784 & 0.0542 & 4.385503 & 4.397159 \\
\hline 19 & 3 & 1 & -2 & 21.1719 & 21.1867 & -0.0148 & 4.193003 & 4.190116 \\
\hline 20 & 0 & 2 & 1 & 22.2072 & 22.0597 & 0.1475 & 3.999811 & 4.026228 \\
\hline 21 & 1 & 2 & -1 & 22.3168 & 22.2631 & 0.0537 & 3.980421 & 3.989901 \\
\hline 22 & 1 & 1 & -3 & 22.9056 & 22.8539 & 0.0517 & 3.879411 & 3.888078 \\
\hline 23 & 2 & 1 & -3 & 23.2235 & 23.2175 & 0.0060 & 3.827029 & 3.827996 \\
\hline 24 & 3 & 1 & 1 & 23.5799 & 23.5778 & 0.0020 & 3.769989 & 3.770312 \\
\hline 25 & 2 & 1 & 2 & 23.9052 & 23.8928 & 0.0124 & 3.719414 & 3.721313 \\
\hline 26 & 1 & 0 & 3 & 24.2932 & 24.2813 & 0.0119 & 3.660871 & 3.662644 \\
\hline 27 & 4 & 1 & -2 & 25.1061 & 25.0883 & 0.0177 & 3.544160 & 3.546625 \\
\hline 28 & 0 & 2 & 2 & 25.5260 & 25.5298 & -0.0038 & 3.486799 & 3.486286 \\
\hline 29 & 2 & 2 & -2 & 25.9086 & 25.9001 & 0.0085 & 3.436166 & 3.437273 \\
\hline 30 & 2 & 2 & 1 & 26.2804 & 26.2533 & 0.0271 & 3.388396 & 3.391828 \\
\hline 31 & 3 & 0 & 2 & 26.2959 & 26.3959 & -0.1000 & 3.386436 & 3.373831 \\
\hline 32 & 1 & 1 & 3 & 26.5095 & 26.4980 & 0.0116 & 3.359625 & 3.361065 \\
\hline 33 & 3 & 2 & -1 & 26.7453 & 26.6547 & 0.0906 & 3.330540 & 3.341653 \\
\hline
\end{tabular}


Synthetic Metals

\begin{tabular}{|c|c|c|c|c|c|c|c|c|}
\hline 34 & 2 & 0 & -4 & 27.1706 & 27.2275 & -0.0569 & 3.279361 & 3.272642 \\
\hline 35 & 3 & 1 & 2 & 28.3665 & 28.2786 & 0.0878 & 3.143775 & 3.153341 \\
\hline 36 & 4 & 1 & 1 & 28.7909 & 28.7974 & -0.0065 & 3.098384 & 3.097704 \\
\hline 37 & 2 & 1 & -4 & 29.1839 & 29.1456 & 0.0384 & 3.057549 & 3.061486 \\
\hline 38 & 3 & 2 & 1 & 29.9193 & 29.8965 & 0.0228 & 2.984052 & 2.986274 \\
\hline 39 & 2 & 2 & 2 & 30.1809 & 30.1890 & -0.0081 & 2.958782 & 2.958005 \\
\hline 40 & 4 & 2 & -1 & 30.4968 & 30.4730 & 0.0237 & 2.928848 & 2.931075 \\
\hline 41 & 3 & 2 & -3 & 31.0392 & 30.9865 & 0.0527 & 2.878890 & 2.883664 \\
\hline 42 & 4 & 2 & -2 & 31.1574 & 31.3351 & -0.1777 & 2.868239 & 2.852376 \\
\hline 43 & 4 & 0 & 2 & 31.5683 & 31.5559 & 0.0124 & 2.831836 & 2.832922 \\
\hline 44 & 4 & 1 & -4 & 32.1303 & 32.1442 & -0.0140 & 2.783575 & 2.782398 \\
\hline 45 & 5 & 0 & -4 & 33.3835 & 33.3772 & 0.0063 & 2.681890 & 2.682383 \\
\hline 46 & 1 & 3 & 1 & 33.5526 & 33.5318 & 0.0208 & 2.668756 & 2.670364 \\
\hline 47 & 2 & 3 & -1 & 33.7773 & 33.7209 & 0.0563 & 2.651520 & 2.655820 \\
\hline 48 & 1 & 2 & -4 & 34.8073 & 34.8034 & 0.0039 & 2.575377 & 2.575657 \\
\hline 49 & 5 & 2 & -2 & 35.0590 & 35.0529 & 0.0060 & 2.557462 & 2.557889 \\
\hline 50 & 6 & 1 & -1 & 35.1067 & 35.1561 & -0.0494 & 2.554094 & 2.550619 \\
\hline 51 & 6 & 0 & 0 & 35.2940 & 35.2855 & 0.0085 & 2.540967 & 2.541560 \\
\hline 52 & 2 & 1 & -5 & 35.7551 & 35.7575 & -0.0025 & 2.509252 & 2.509085 \\
\hline 53 & 4 & 0 & -5 & 35.8397 & 35.8402 & -0.0005 & 2.503519 & 2.503485 \\
\hline 54 & 1 & 1 & -5 & 36.3962 & 36.3916 & 0.0046 & 2.466509 & 2.466812 \\
\hline 55 & 5 & 2 & -3 & 36.7349 & 36.7072 & 0.0277 & 2.444543 & 2.446324 \\
\hline 56 & 3 & 3 & -2 & 36.8920 & 36.8869 & 0.0050 & 2.434492 & 2.434813 \\
\hline 57 & 4 & 1 & -5 & 37.4328 & 37.4329 & -0.0001 & 2.400550 & 2.400545 \\
\hline 58 & 1 & 3 & -3 & 37.9624 & 37.9659 & -0.0036 & 2.368274 & 2.368059 \\
\hline 59 & 7 & 0 & -2 & 38.7470 & 38.7478 & -0.0007 & 2.322101 & 2.322059 \\
\hline 60 & 5 & 2 & 1 & 39.0791 & 39.0760 & 0.0031 & 2.303131 & 2.303307 \\
\hline 61 & 6 & 2 & -2 & 39.5417 & 39.5291 & 0.0126 & 2.277246 & 2.277942 \\
\hline 62 & 5 & 1 & -5 & 39.6442 & 39.6453 & -0.0011 & 2.271595 & 2.271533 \\
\hline 63 & 6 & 2 & -1 & 39.7978 & 39.7865 & 0.0113 & 2.263177 & 2.263795 \\
\hline 64 & 6 & 1 & 1 & 40.0478 & 40.0440 & 0.0037 & 2.249627 & 2.249829 \\
\hline 65 & 4 & 3 & -3 & 41.3002 & 41.3037 & -0.0035 & 2.184252 & 2.184075 \\
\hline 66 & 5 & 3 & -1 & 42.5124 & 42.5084 & 0.0041 & 2.124733 & 2.124926 \\
\hline 67 & 6 & 1 & -5 & 42.6280 & 42.6328 & -0.0047 & 2.119238 & 2.119014 \\
\hline 68 & 2 & 1 & -6 & 42.7466 & 42.7674 & -0.0208 & 2.113637 & 2.112655 \\
\hline
\end{tabular}


Synthetic Metals

\begin{tabular}{|c|c|c|c|c|c|c|c|c|}
\hline 69 & 3 & 3 & -4 & 42.9185 & 42.9352 & -0.0167 & 2.105568 & 2.104787 \\
\hline 70 & 1 & 4 & 0 & 43.1614 & 43.1480 & 0.0133 & 2.094279 & 2.094895 \\
\hline 71 & 4 & 2 & 3 & 43.1914 & 43.2851 & -0.0936 & 2.092891 & 2.088580 \\
\hline 72 & 0 & 4 & 1 & 43.3875 & 43.3738 & 0.0137 & 2.083887 & 2.084512 \\
\hline 73 & 5 & 3 & -3 & 44.0730 & 44.0603 & 0.0127 & 2.053052 & 2.053615 \\
\hline 74 & 6 & 1 & 2 & 44.2922 & 44.2823 & 0.0098 & 2.043400 & 2.043831 \\
\hline 75 & 7 & 1 & 1 & 45.9924 & 45.9955 & -0.0032 & 1.971739 & 1.971611 \\
\hline 76 & 5 & 3 & -4 & 46.7107 & 46.7097 & 0.0010 & 1.943079 & $1.94311 \varepsilon$ \\
\hline 77 & 3 & 3 & -5 & 47.5328 & 47.5243 & 0.0086 & 1.911370 & 1.911694 \\
\hline 78 & 6 & 0 & 3 & 48.1612 & 48.1633 & -0.0022 & 1.887891 & 1.887810 \\
\hline 79 & 0 & 4 & 3 & 48.3762 & 48.3579 & 0.0183 & 1.879999 & 1.880667 \\
\hline 80 & 5 & 0 & 4 & 48.7184 & 48.7636 & -0.0452 & 1.867591 & 1.865966 \\
\hline 81 & 3 & 1 & -7 & 49.7051 & 49.7093 & -0.0042 & 1.832805 & 1.832660 \\
\hline 82 & 7 & 1 & 2 & 50.1595 & 50.1684 & -0.0090 & 1.817261 & 1.816957 \\
\hline 83 & 4 & 4 & 1 & 51.1333 & 51.1257 & 0.0076 & 1.784914 & 1.785162 \\
\hline 84 & 1 & 2 & 6 & 51.6075 & 51.5936 & 0.0139 & 1.769621 & 1.770067 \\
\hline 85 & 5 & 4 & -3 & 52.9642 & 52.9837 & -0.0194 & 1.727444 & 1.726856 \\
\hline 86 & 1 & 3 & -6 & 53.7961 & 53.7945 & 0.0016 & 1.702679 & 1.702726 \\
\hline 87 & 4 & 4 & 2 & 54.0872 & 54.0900 & -0.0027 & 1.694198 & 1.694120 \\
\hline 88 & 2 & 2 & 6 & 54.5888 & 54.5902 & -0.0015 & 1.679813 & 1.679771 \\
\hline 89 & 7 & 1 & 3 & 55.1849 & 55.1886 & -0.0037 & 1.663068 & 1.662967 \\
\hline 90 & 4 & 2 & 5 & 55.3163 & 55.3315 & -0.0152 & 1.659429 & 1.659010 \\
\hline 91 & 7 & 3 & 1 & 55.8042 & 55.8184 & -0.0142 & 1.646070 & 1.645686 \\
\hline 92 & 9 & 2 & -1 & 56.5164 & 56.5263 & -0.0099 & 1.627006 & 1.626744 \\
\hline 93 & 3 & 5 & -1 & 57.0031 & 57.0288 & -0.0258 & 1.614266 & 1.613598 \\
\hline 94 & 3 & 5 & -2 & 57.7032 & 57.6818 & 0.0214 & 1.596332 & 1.596874 \\
\hline 95 & 5 & 4 & -5 & 58.5906 & 58.6012 & -0.0105 & 1.574252 & 1.573994 \\
\hline 96 & 7 & 4 & -2 & 59.0391 & 59.0351 & 0.0040 & 1.563359 & 1.563455 \\
\hline 97 & 7 & 3 & -6 & 59.7805 & 59.7786 & 0.0019 & 1.545728 & 1.545773 \\
\hline 98 & 4 & 5 & -3 & 60.9353 & 60.9373 & -0.0020 & 1.519172 & 1.519128 \\
\hline 99 & 4 & 4 & -6 & 61.5236 & 61.5296 & -0.0060 & 1.506050 & 1.505917 \\
\hline 100 & 6 & 4 & 2 & 62.1657 & 62.1457 & 0.0200 & 1.492026 & 1.492458 \\
\hline 101 & 10 & 1 & -6 & 62.9659 & 62.9634 & 0.0025 & 1.474976 & 1.475029 \\
\hline 102 & 8 & 4 & -3 & 63.7285 & 63.7234 & 0.0051 & 1.459152 & 1.459258 \\
\hline 103 & 7 & 3 & 3 & 64.0111 & 64.0207 & -0.0097 & 1.453391 & 1.453195 \\
\hline
\end{tabular}


Synthetic Metals

\begin{tabular}{|c|c|c|c|c|c|c|c|c|}
\hline 104 & 8 & 3 & 2 & 65.0028 & 65.0134 & -0.0106 & 1.433594 & 1.433387 \\
\hline 105 & 8 & 0 & 4 & 65.9165 & 65.8920 & 0.0245 & 1.415918 & 1.416386 \\
\hline 106 & 2 & 3 & 7 & 67.2831 & 67.2990 & -0.0159 & 1.390443 & 1.390153 \\
\hline 107 & 1 & 3 & -8 & 67.6220 & 67.6225 & -0.0005 & 1.384296 & 1.384287 \\
\hline 108 & 1 & 5 & 5 & 68.7200 & 68.7107 & 0.0093 & 1.364832 & 1.364994 \\
\hline 109 & 7 & 5 & -3 & 69.0997 & 69.1062 & -0.0064 & 1.358257 & 1.358146 \\
\hline 110 & 7 & 3 & -8 & 69.7607 & 69.7685 & -0.0078 & 1.346995 & 1.346864 \\
\hline 111 & 3 & 6 & 1 & 70.3788 & 70.3802 & -0.0014 & 1.336673 & 1.336650 \\
\hline 112 & 12 & 1 & -2 & 71.2098 & 71.1997 & 0.0101 & 1.323100 & 1.323262 \\
\hline 113 & 9 & 0 & -9 & 72.0235 & 72.0113 & 0.0122 & 1.310141 & 1.310333 \\
\hline 114 & 8 & 0 & 5 & 72.3790 & 72.3804 & -0.0013 & 1.304579 & 1.304558 \\
\hline 115 & 2 & 6 & -4 & 73.0009 & 73.0046 & -0.0037 & 1.294992 & 1.294935 \\
\hline 116 & 12 & 2 & -3 & 73.3905 & 73.3853 & 0.0052 & 1.289077 & 1.289156 \\
\hline 117 & 0 & 6 & 4 & 73.8753 & 73.8725 & 0.0028 & 1.281812 & 1.281853 \\
\hline 118 & 1 & 5 & 6 & 74.1796 & 74.1766 & 0.0030 & 1.277305 & 1.277348 \\
\hline 119 & 8 & 5 & 0 & 75.0217 & 75.0335 & -0.0118 & 1.265042 & 1.264872 \\
\hline 120 & 10 & 4 & -5 & 75.6552 & 75.6730 & -0.0179 & 1.256016 & 1.255764 \\
\hline 121 & 2 & 5 & -7 & 75.9135 & 75.9158 & -0.0022 & 1.252383 & 1.252352 \\
\hline 122 & 8 & 5 & -5 & 76.2065 & 76.2136 & -0.0071 & 1.248296 & 1.248198 \\
\hline 123 & 9 & 4 & 2 & 77.8263 & 77.8104 & 0.0159 & 1.226314 & 1.226524 \\
\hline 124 & 12 & 3 & -3 & 78.2940 & 78.2925 & 0.0015 & 1.220156 & 1.220175 \\
\hline 125 & 6 & 6 & 1 & 79.3502 & 79.3465 & 0.0037 & 1.206545 & 1.206593 \\
\hline 126 & 5 & 1 & 8 & 79.5943 & 79.5848 & 0.0095 & 1.203458 & 1.203577 \\
\hline 127 & 13 & 2 & -2 & 81.1730 & 81.1726 & 0.0004 & 1.183991 & 1.183996 \\
\hline 128 & 14 & 0 & -4 & 83.1271 & 83.1240 & 0.0031 & 1.161051 & 1.161086 \\
\hline 129 & 2 & 0 & 10 & 83.6355 & 83.6271 & 0.0084 & 1.155281 & 1.155376 \\
\hline 130 & 3 & 3 & 9 & 86.9193 & 86.9181 & 0.0012 & 1.119875 & 1.119888 \\
\hline 131 & 3 & 7 & 3 & 88.2043 & 88.2123 & -0.0080 & 1.106847 & 1.106768 \\
\hline
\end{tabular}

